\title{
Method for designing the optimal sealing depth in methane drainage boreholes to realize efficient drainage
}

\author{
Minghao Yi $\mathbf{Y}^{1,2,3} \cdot$ Liang Wang ${ }^{1,2,3} \cdot$ Congmeng Hao ${ }^{1,2,3} \cdot$ Qingquan Liu ${ }^{1,2,3}$ • \\ Zhenyang Wang ${ }^{1,2,3}$
}

Received: 5 January 2021/Revised: 22 February 2021/Accepted: 17 June 2021/Published online: 14 July 2021

(C) The Author(s) 2021

\begin{abstract}
The purpose of underground methane drainage technology is to prevent methane disasters and enable the efficient use of coal mine methane (CMM), and the sealing depth is a key factor that affects the performance of underground methane drainage. In this work, the layouts of in-seam and crossing boreholes are considered to analyze the stress distribution and failure characteristics of roadway surrounding rock through a numerical simulation and field stress investigation to determine a reasonable sealing depth. The results show that the depths of the plastic and elastic zones in two experimental coal mines are 16 and $20 \mathrm{~m}$ respectively. Borehole sealing minimizes the air leakage through the fractures around the roadway when the sealing material covers the failure and plastic zones, and the field test results for CMM drainage at different sealing depths indicate that the CMM drainage efficiency increases with increasing sealing depth but does not change once the sealing depth exceeds the plastic zone. Moreover, sealing in the high-permeability roadway surrounding rock does not have a strong influence on the borehole sealing performance. Considering these findings, a new CMM drainage system for key sealing in the low-permeability zone was developed that is effective for improving the CMM drainage efficiency and prolonging the high-concentration CMM drainage period. The proposed approach offers a valuable quantitative analysis method for selecting the optimum sealing parameters for underground methane drainage, thereby improving considerably the drainage and utilization rates of CMM.
\end{abstract}

Keywords Coal mine methane $\cdot$ Methane drainage $\cdot$ Borehole sealing $\cdot$ Mining safety $\cdot$ Methane utilization

\section{Introduction}

Coal mine methane $(\mathrm{CMM})$ is a byproduct of coal production and comprises mainly $\mathrm{CH}_{4}$ (Karacan et al. 2011; Fu et al. 2020). CMM is a clean and efficient fuel that can

Liang Wang

wangliang@ cumt.edu.cn

1 Key Laboratory of Coal Methane and Fire Control, Ministry of Education, China University of Mining and Technology, Xuzhou 221116, Jiangsu, China

2 National Engineering Research Center for Coal Gas Control, China University of Mining and Technology, Xuzhou 221116, Jiangsu, China

3 School of Safety Engineering, China University of Mining and Technology, Xuzhou 221116, Jiangsu, China be used for power generation, heating, and civil usage, but its presence is a critical threat to the safety of coal mining (Wang et al. 2020b). In general, underground methane drainage is an effective means of reducing the amount of CMM, thereby preventing methane disasters (Wang et al. 2014; Zhao et al. 2020). Moreover, because the greenhouse effect of methane is approximately 25 times that of carbon dioxide, CMM drainage and utilization can help to reduce greenhouse gas emissions and alleviate global warming (Kholod et al. 2020; Wang et al. 2019a). However, the utilization rate of CMM in China in 2015 was only 35.3\%, resulting in considerable energy loss and environmental pollution (National Energy Administration 2016). Air leakage due to poor borehole sealing performance is the main cause of low gas drainage efficiency (Zheng et al. 2016; Zhang et al. 2020b; Wang et al. 2019b; Xia et al. 2014). 
As shown in Fig. 1, air leakage occurs mainly because of the fractures around roadways and boreholes, as well as failure of the sealing material (Islam and Shinjo 2009, Liu et al. 2019, Fuenkajorn and Daemen 2012, Liu et al. 2014b, Zhao et al. 2015, Zhang et al. 2020b). In recent years, there has been extensive research into how to improve borehole sealing performance. Liu et al. (2014a) proposed a new sealing method to provide high sealing performance by means of multiple grouting under high grouting pressure. Hao et al. (2018) studied the anti-seepage effect of silica sol and conducted an experiment to show its effectiveness in improving borehole sealing. Hu et al. (2020) analyzed the effect of surrounding rock creep on borehole sealing and proposed the method of filling the remaining voids by repeated grouting to block new fractures during CMM drainage. Based on the distribution of air-leakage fractures around boreholes, some new technologies using fine expansive particles to plug such fractures were proposed (Zhang et al. 2020a 2019; Xia et al. 2014). All of the above methods work by injecting sealing materials into fractures to block as many as possible around boreholes.

Also, the mechanisms for air leakage have been studied, and air leakage is associated strongly with the stress distribution after roadway and borehole excavations. Xue et al. (2017) used a hydro-mechanical model to obtain the permeability and stress distribution characteristics of roadway surrounding rock, and they divided the roadway surrounding rock into four zones. Hu et al. (2015) investigated the relationship between permeability and effective stress, and they obtained the gas flow in the different zones of surrounding rock. Chen (2012) found good agreement between stress and drill cutting weight and established a quantitative relationship between the two. Yang et al. (2018) determined directly the permeability of a coal seam around a roadway, and they reasoned that serious leakage occurs in high-permeability zones with an inappropriate sealing depth. Liu et al. (2020) characterized the gas flow around a borehole, and their results showed that air leakage is reduced by increasing the sealing area. Note that the fractures due to roadway excavation are distributed widely in the roadway surrounding rock, and increasing the coverage of the grouting zone in the failure zone is challenging for those sealing methods that involve only borehole grouting. Based on the permeability and stress distribution characteristics, the sealing section in low-permeability zones is of great benefit in preventing air leakage through fractures around roadways. However, many coal mines in China, the borehole sealing depth and length are generally determined via experience, and that process can lead to unsatisfactory borehole sealing performance or the generation of CMM drainage blank zones, given that the geological conditions become increasingly complex with
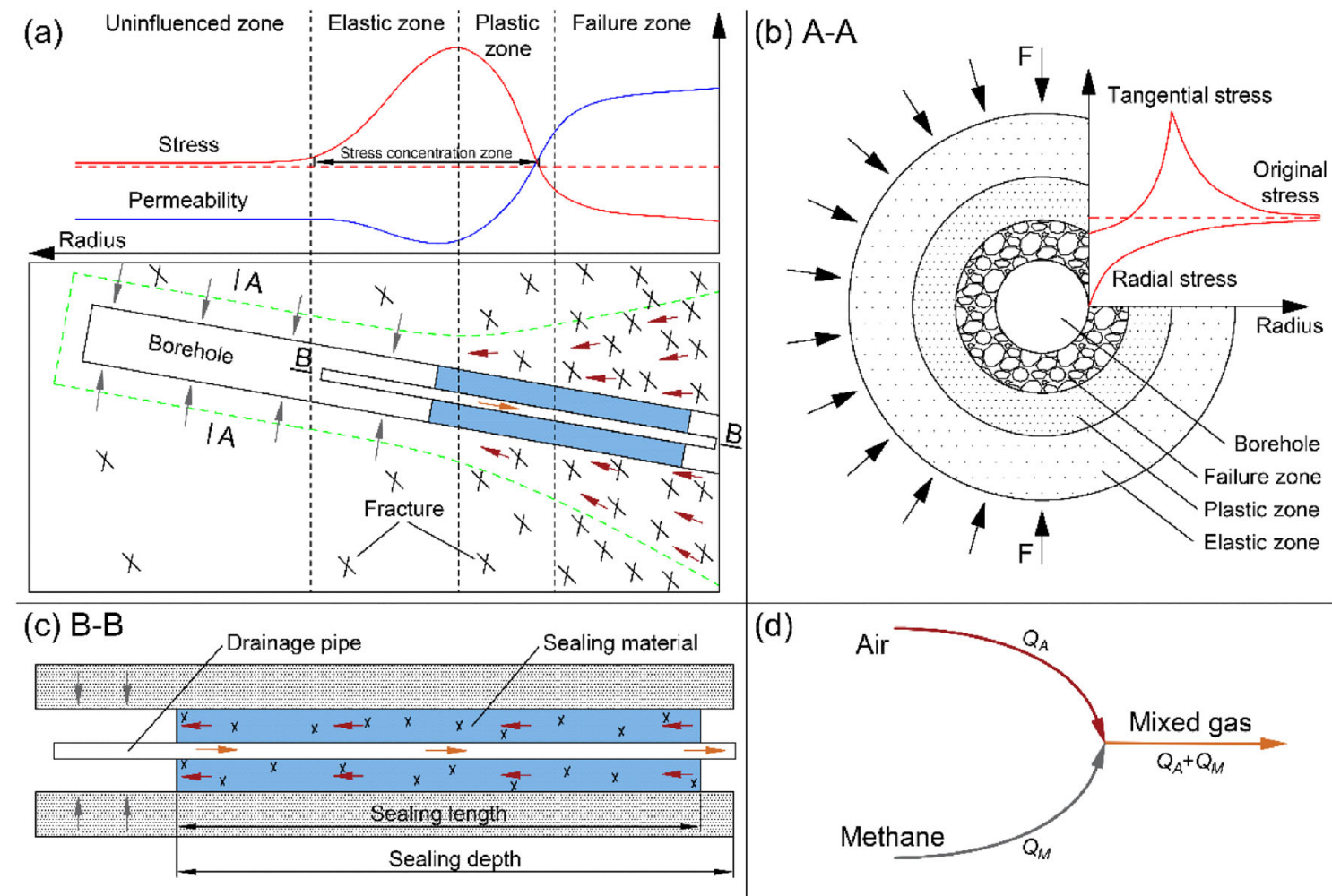

Fig. 1 Sealing failure for a coal mine methane (CMM) drainage borehole: a fractures around roadway; b secondary fractures around borehole; c failure of sealing material; $\mathbf{d}$ composition of mixed gas 
increasing mining depth. As such, it is essential to determine a reasonable borehole sealing depth and length to realize effective CMM drainage.

Therefore, in the present study, the stress distribution in roadway surrounding rock is determined via numerical simulations and field verifications, and a new CMM drainage technique is developed for key sealing in the lowpermeability zone. To verify the practicality and efficiency of the proposed technique, it was used in field applications in coal mines in Xutuan and Qinan in China.

\section{Experiments and numerical simulations}

\subsection{Test sites}

The test sites for this study were working face $7_{2} 314$ in the Xutuan coal mine and working face $7_{2} 42$ in the Qinan coal mine, and the practical measured parameters of the rock formations in these two working faces are given in Table 1. To drain the CMM and prevent such outbursts, in-seam boreholes were used to extract the CMM in the considered working face in the Xutuan coal mine, whereas CMM drainage was performed using upward crossing boreholes in the Qinan coal mine. However, the presence of low permeability and air leakage led to low CMM concentration.

\subsection{Numerical simulation}

The commercial software FLAC-3D was used to simulate the stress distributions after roadway excavation based on the Mohr-Coulomb strength criterion. The model of the Xutuan coal mine was $40 \mathrm{~m}$ wide, $80 \mathrm{~m}$ long, and $60 \mathrm{~m}$ high and was divided into five layers; the sides and bottom of this model were roller boundaries, and the top was a constant-stress boundary with a vertical stress of 13.65 MPa. With a width of $5 \mathrm{~m}$ and height of $4 \mathrm{~m}$, the roadway in the model of the Xutuan coal mine was arranged in coal seam 72 . The model of the Qinan coal mine was $60 \mathrm{~m}$ wide, $90 \mathrm{~m}$ long, and $120 \mathrm{~m}$ high and was divided into five layers; the sides and bottom of this model were roller boundaries, and the top was a constant-stress boundary with a vertical stress of $9.6 \mathrm{MPa}$. With a width of $4 \mathrm{~m}$, a wall height of $2 \mathrm{~m}$, and an arch height of $2 \mathrm{~m}$, the bed plate roadway in the model of the Qinan coal mine was located below coal seam $7_{2}$ at a normal distance of $20 \mathrm{~m}$. The physical modes are shown in Fig. 2, and the parameters are given in Table 1 .

Also, the stress distributions on two monitoring lines are plotted in Fig. 3. With decreasing distance to the roadway, the maximal principal stress $\sigma_{1}$ and intermediate principal stress $\sigma_{2}$ first increase and then decrease rapidly to around zero, and the minimal principal stress $\sigma_{3}$ decreases gradually to nearly zero near the roadway. The numerical simulation results show that roadway excavation causes $\sigma_{3}$ to decrease $\sigma_{1}$ and $\sigma_{2}$ to increase initially. According to the Mohr-Coulomb failure criterion, after the differential stress $\sigma_{1}-\sigma_{3}$ reaches the yield strength, plastic failure occurs in the roadway surrounding rock, whereupon $\sigma_{1}$ and $\sigma_{2}$ start to decrease. This stress relief reduces the effective stress, which increases the internal fracture openings and thus the permeability. Additionally, the internal fractures of the roadway surrounding rock expand, propagate, and connect in the course of plastic deformation, resulting in increased permeability. Therefore, the sealing depth of the underground methane drainage borehole should be larger than the radius of stress relief zone.

Table 1 Parameters of coal mines used for numerical simulation

\begin{tabular}{|c|c|c|c|c|c|c|c|c|}
\hline Site & Stratum & $\begin{array}{l}\text { Density } \\
\left(\mathrm{kg} / \mathrm{m}^{3}\right)\end{array}$ & $\begin{array}{l}\text { Bulk modulus } \\
(\mathrm{GPa})\end{array}$ & $\begin{array}{l}\text { Shear modulus } \\
(\mathrm{GPa})\end{array}$ & $\begin{array}{l}\text { Cohesion } \\
\text { (MPa) }\end{array}$ & $\begin{array}{l}\text { Internal friction } \\
\text { angle }\left({ }^{\circ}\right)\end{array}$ & $\begin{array}{l}\text { Strength of } \\
\text { extension (MPa) }\end{array}$ & $\begin{array}{l}\text { Thickness } \\
\text { (m) }\end{array}$ \\
\hline \multirow[t]{5}{*}{ Xutuan } & Main roof & 2650 & 5.46 & 4.1 & 4.21 & 36.15 & 5.34 & 12.0 \\
\hline & $\begin{array}{l}\text { Immediate } \\
\text { roof }\end{array}$ & 2300 & 2.50 & 2.0 & 3.30 & 18.26 & 2.10 & 3.0 \\
\hline & $7_{2}$ coal seam & 1450 & 1.50 & 1.2 & 1.00 & 18.00 & 1.50 & 4.5 \\
\hline & $\begin{array}{l}\text { Immediate } \\
\text { bottom }\end{array}$ & 2300 & 2.50 & 2.0 & 3.30 & 18.26 & 2.10 & 2.5 \\
\hline & Main bottom & 2650 & 5.46 & 4.1 & 4.21 & 36.15 & 5.34 & 18.0 \\
\hline \multirow[t]{5}{*}{ Qinan } & Roof & 2500 & 3.20 & 2.3 & 2.00 & 29.00 & 2.30 & 9.0 \\
\hline & $7_{1}$ coal seam & 1450 & 1.50 & 1.2 & 1.00 & 18.00 & 1.00 & 1.5 \\
\hline & Intercalation & 2250 & 2.80 & 2.1 & 1.50 & 25.00 & 1.50 & 5.0 \\
\hline & $7_{2}$ coal seam & 1450 & 1.50 & 1.2 & 1.00 & 18.00 & 1.00 & 2.5 \\
\hline & Bottom & 2750 & 3.70 & 3.3 & 2.90 & 32.00 & 2.10 & 42.0 \\
\hline
\end{tabular}




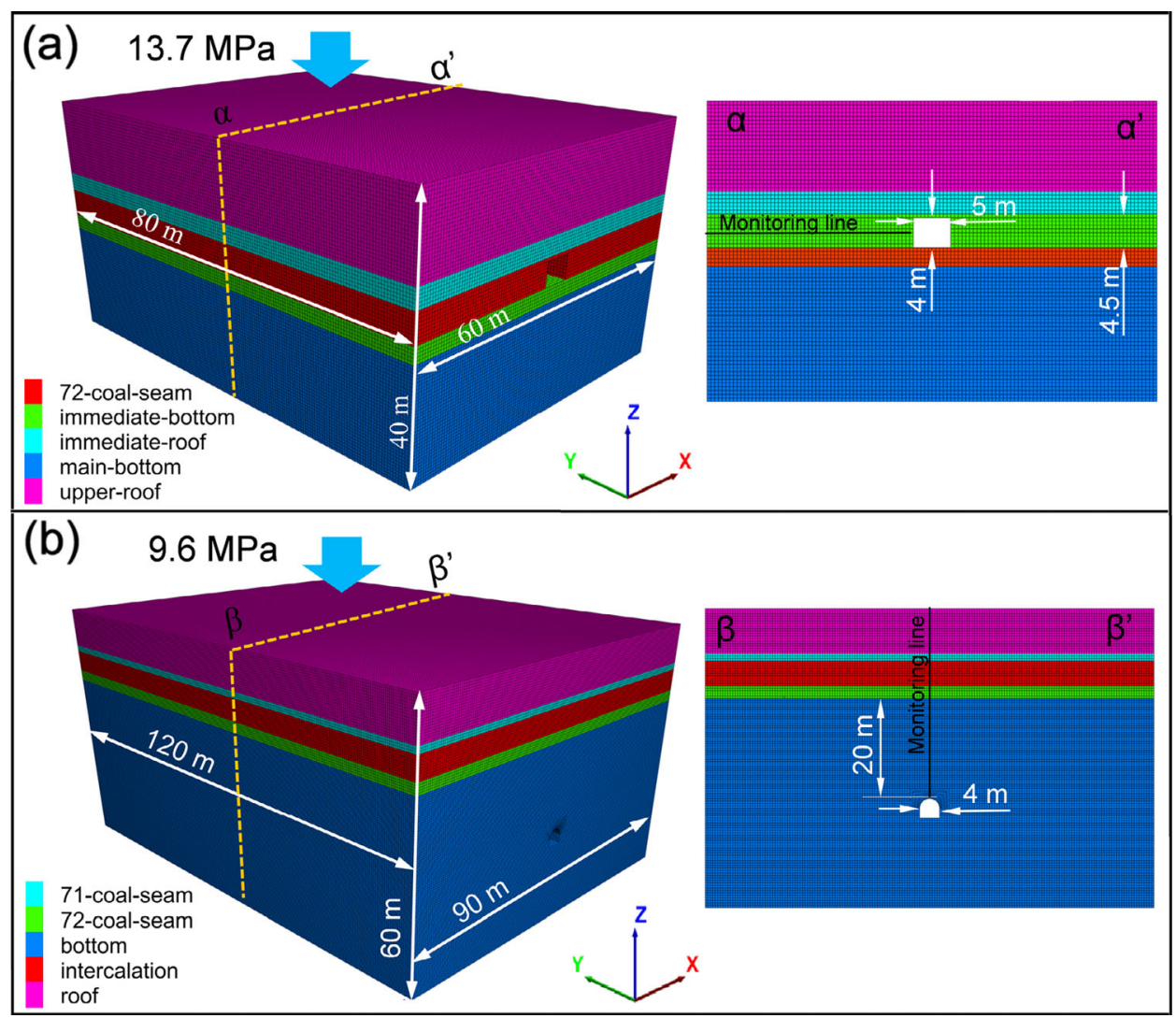

Fig. 2 Numerical simulation models of a Xutuan and $\mathbf{b}$ Qinan coal mines

\subsection{Field investigations of stress distributions around roadways}

The drilling-rig response is used widely to reflect the stress distribution of the roadway surrounding rock. Generally, the methods of drill cutting and drill cutting torque are used to perform field stress investigations (Zhai et al. 2018; Kalantari et al. 2018). Under the influence of a single factor, the drill cutting weight $(S)$ and coal stress are correlated positively (Chen 2012). Additionally, the stress distribution around the roadway can be reflected by measuring the operating parameters of the drilling rig ( $\mathrm{Li}$ et al. 2020b; Zhang et al. 2016a), the main ones being the hydraulic-motor inlet oil pressure $\left(P_{1}\right)$, which makes the drill bit rotate to break the rock, and the oil-cylinder inlet oil pressure $\left(P_{2}\right)$, which pushes the drill rod toward the bottom of the borehole. For the same coal and rock materials under the same stress, a higher drilling velocity (v) corresponds to larger drilling thrust and torque (Li et al. 2020a). For the automatic hydraulic drilling rig used in these field tests, 1-m-long drill rods and drill bits with an outer diameter of $113 \mathrm{~mm}$ were used. The drilling time and the weight of drill cuttings were recorded in each drilling cycle, so the drilling velocity could be calculated according to the drilling time required for each drill rod. Additionally, the rotating and propelling forces of a drill rod were applied by two separate hydraulic systems that were monitored by using the drilling rig's own pressure gauges. The drilling parameters of six in-seam gas drainage boreholes in the Xutuan coal mine were monitored. In the Qinan coalmine, three boreholes perpendicular to the roadway wall were constructed in adjacent drilling sites, and the average drilling parameters of several boreholes are shown in Fig. 4.

As shown in Fig. 4a, because of stress relief in the failure zone, the drill cutting weight per unit length of the test boreholes was small and stable when the drilling depth was less than $10 \mathrm{~m}$, while the propelling velocity and the propelling and rotating pressures were basically stable. This shows that the stress of the surrounding rock pressure in this zone was small and did not change obviously. When the drilling depth was less than $16 \mathrm{~m}$, the propelling and rotating pressures increased, the propelling velocity was basically stable, but the drilling cutting weight increased rapidly and reached a maximum value of $54.4 \mathrm{~kg} / \mathrm{m}$ at a drilling depth of $16 \mathrm{~m}$, which indicates that the stress of the roadway surrounding rock increased and reached its maximum value at $16 \mathrm{~m}$. The propelling velocity then started to decrease because of the decreasing propelling and rotating pressures, but the drilling cutting weight decreased and 

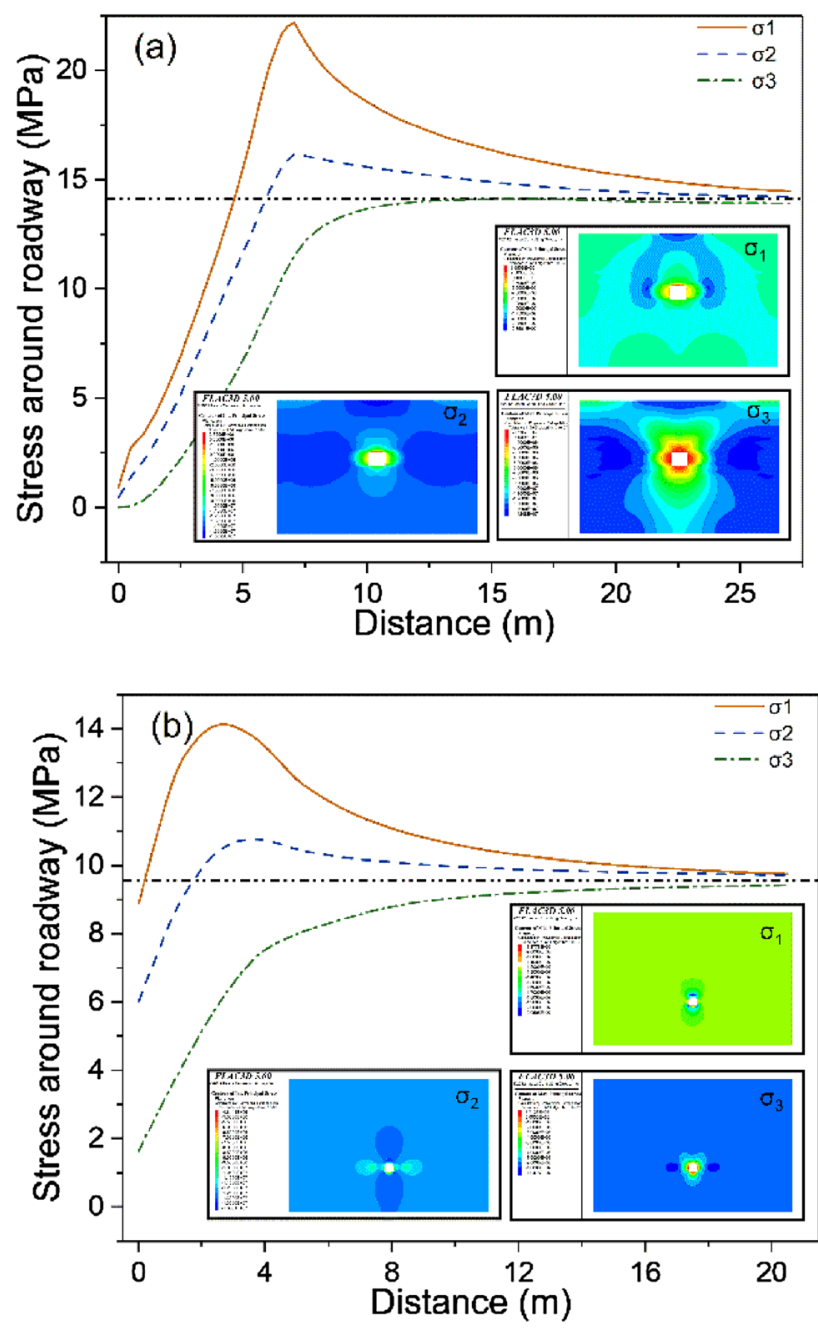

Fig. 3 Stress distributions around roadways in a Xutuan and b Qinan coal mines

finally was constant when the drilling depth exceeded $20 \mathrm{~m}$, indicating that the stress of the roadway surrounding rock decreased and became stable. Therefore, the range of the stress concentration zone was 10-20 m, and the radii of the failure, plastic, and elastic zones were 10, 16, and $20 \mathrm{~m}$, respectively.

Because it was difficult to collect the drill cuttings when drilling the upward crossing boreholes, the field stress investigation in the Qinan coal mine was conducted by analyzing the operating parameters. The variations in the propelling and rotating pressures and the drilling velocity are shown in Fig. 4b. When the drilling depth was less than $16 \mathrm{~m}$, the propelling and rotating pressures increased while the propelling velocity decreased. The increased drilling resistance shows that the stress of the roadway surrounding rock increased. After that, however, the propelling and rotating pressures decreased while the propelling velocity increased, which shows that the stress of the roadway surrounding rock started to decrease. When the drilling
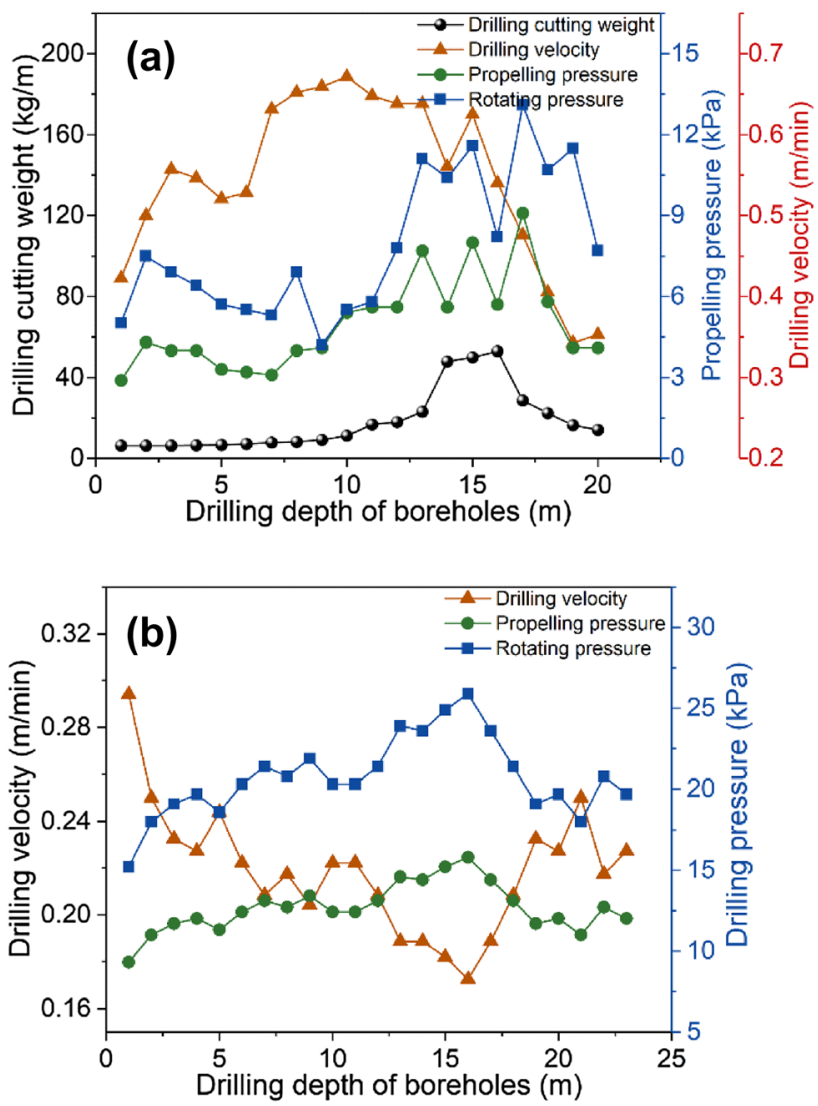

Fig. 4 Stress distributions around roadways in a Xutuan and b Qinan coal mines

depth exceeded $20 \mathrm{~m}$, the three values were basically stable, and the drilling rod entered the uninfluenced zone. According to the response of the drilling rig, the range of the stress concentration zone in the Qinan coal mine was 10-20 m, and the radii of the failure, plastic, and elastic zones were 10,16 , and $20 \mathrm{~m}$, respectively.

From analyzing the permeability evolution in the roadway surrounding rock, the methane in the failure and plastic zones-which have high permeability—can flow into the roadway spontaneously, thereby generating a methane self-emission zone in which the methane content is significantly reduced. In this case, the borehole sealing section should enter the low-permeability elastic zone to reduce the air leakage through the fractures in the highpermeability zone (Cai and Kaiser 2014; Zhang et al. 2016b). However, the methane cannot be extracted in the borehole sealing section, and a methane drainage blank zone may be generated in the low-permeability zone if the sealing length of an in-seam borehole is excessively large (Meng et al. 2016; Xue et al. 2017). In this blank zone, the risk of a methane disaster persists throughout and even increases because of the stress concentration and high methane pressure. Therefore, the sealing depth of an inseam borehole should be less than that of the low- 
permeability elastic zone. For a crossing borehole, its entire rock section can be sealed to ensure high sealing performance, but doing so increases the construction cost considerably. To balance the economic cost and the sealing performance, the sealing depth of a crossing borehole should be slightly larger than the radius of the plastic zone. In summary, the sealing depth of underground methane drainage boreholes can be determined based on the radius of the plastic zone. According to the results for the stress distributions around the roadways, the sealing depth should be $16 \mathrm{~m}$ for the in-seam boreholes in the Xutuan coal mine and the crossing boreholes in the Qinan coal mine.

\section{Field verification tests}

\subsection{CMM drainage for different sealing depths}

The results of the numerical simulations and field stress investigations indicate that the theoretical and field stress peaks occurred at 12 and $16 \mathrm{~m}$ in the Xutuan coal mine and at 10 and $16 \mathrm{~m}$ in the Qinan coal mine, respectively. CMM drainage experiments for different sealing depths were performed to verify the rationality of the designed borehole sealing depth. Polyurethane and cement grout were the sealing materials in the field tests, and the borehole sealing is shown schematically in Fig. 5. First, polyurethane is set up at both ends of the sealing part to fix the gas drainage pipe in the borehole and form the grouting space, then cement is injected into the interior space between the two polyurethane ends with a certain sealing pressure to plug the fractures around the borehole.

As illustrated in Fig. 6, two groups of in-seam boreholes with different sealing depths were designed in the Xutuan coal mine. Each group contained three boreholes with sealing depths of 12,16 , and $20 \mathrm{~m}$, and the space between the boreholes was $30 \mathrm{~m}$. After completing the borehole sealing, the in-seam boreholes were connected to the CMM drainage network. The methane parameters of the boreholes were measured continuously for 14 weeks, and the

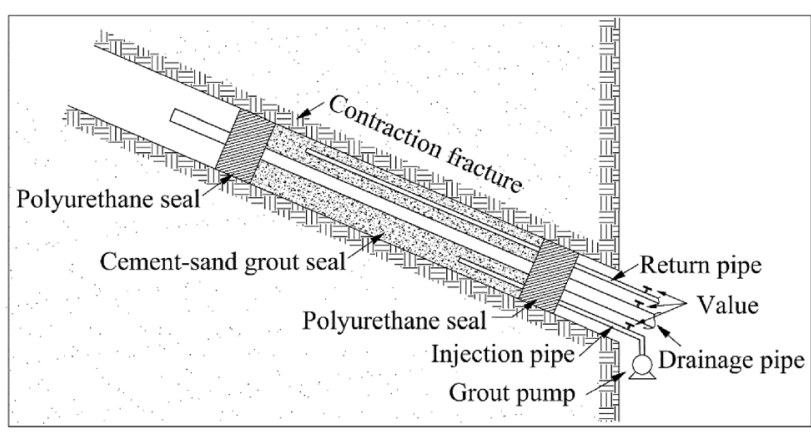

Fig. 5 Illustration of sealing a gas drainage borehole

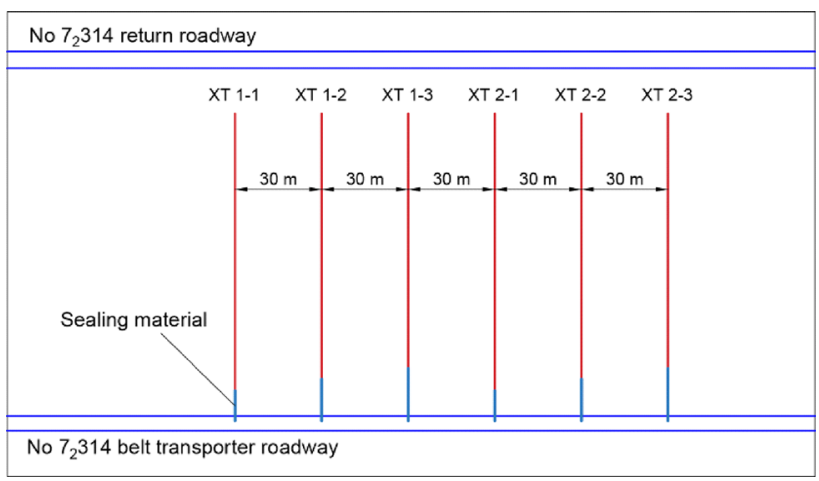

Fig. 6 Layout of in-seam boreholes in Xutuan coal mine

methane flow and concentration in the Xutuan coal mine varied as shown in Fig. 7. In particular, the methane flow and concentration in the boreholes decreased gradually over time, and the CMM drainage process could be divided into two stages according to the critical concentration of the methane utilization (30\%). The first stage was the highconcentration CMM drainage period (methane concentration greater than $30 \%$ ), and the extracted high-concentration CMM could be used directly. In the second stage, pertaining to low-concentration $\mathrm{CMM}$ drainage, the
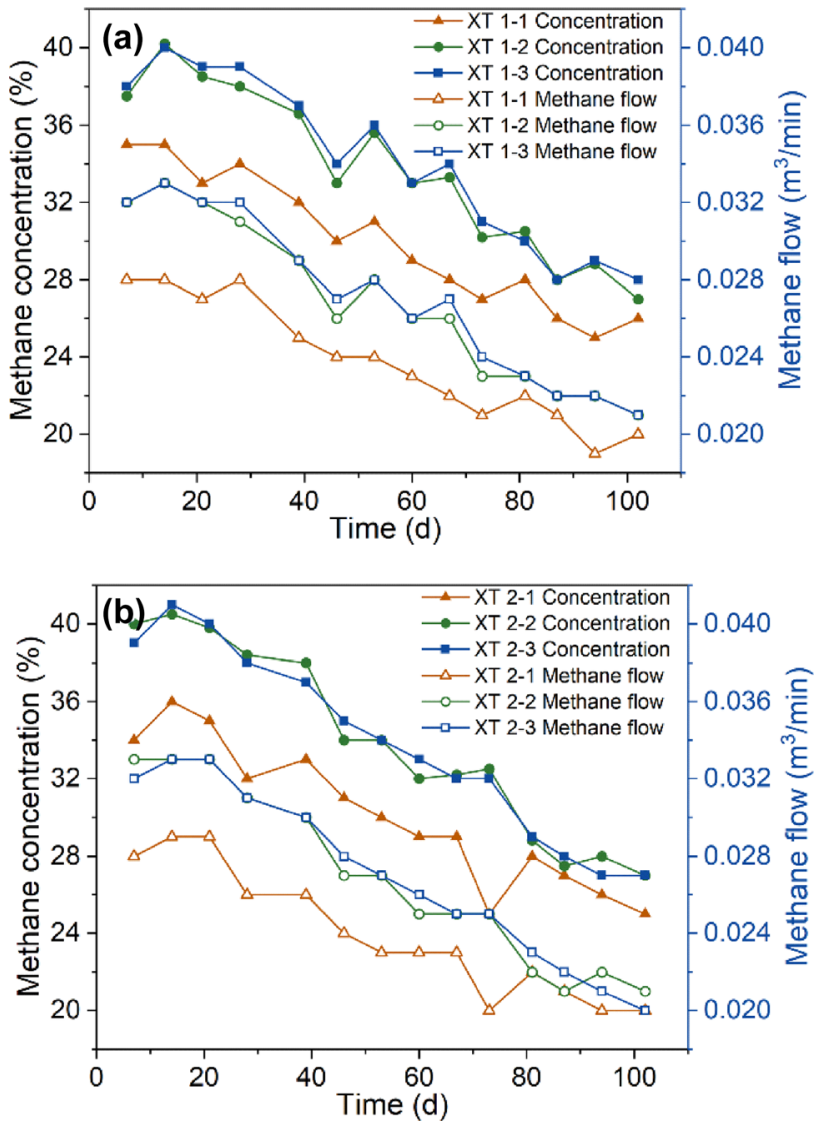

Fig. 7 Concentration-time curves of methane for different sealing depths in Xutuan coal mine 
methane concentration decreased to less than the critical concentration; such low-concentration CMM is generally difficult to use and may lead to environmental pollution. The methane concentrations of boreholes with different sealing depths were compared, and it was noted that increasing the sealing depth improved the CMM drainage efficiency considerably. The methane flow and concentration of the XT 1-2 and XT 2-2 boreholes with a sealing depth of $16 \mathrm{~m}$ were significantly higher than those of the XT 1-1 and XT 2-1 boreholes with a sealing depth of $12 \mathrm{~m}$, and the high-concentration CMM drainage period was extended from approximately 50 to $80 \mathrm{~d}$. However, the methane flow and concentration and high-concentration CMM drainage period of the XT 1-3 and XT 2-3 boreholes were nearly the same as those of the XT $1-2$ and XT 2-2 boreholes when the sealing depth was increased from 16 to $20 \mathrm{~m}$.

When the stress distributions of different cross sections of the roadway are assumed to be same, the sealing performance of the crossing boreholes with the same depth but different azimuth angles varies. When a borehole deviates by $60^{\circ}$ from the vertical plane of the roadway, its effective sealing depth (represented as the vertical distance from the inner end point of the borehole sealing section to the roadway side) is only half that of a vertical borehole. Therefore, two groups of crossing boreholes with different sealing depths were designed in the Qinan coal mine, with each group comprising three boreholes with a spacing of $30 \mathrm{~m}$. The layouts and drilling parameters of the experimental crossing boreholes in the Qinan coal mine are presented in Fig. 8 and Table 2.

The methane flow and concentration of the crossing boreholes in the Qinan coal mine varied with time as shown in Fig. 9. The methane concentrations of the QN 1-3 and QN 1-1 boreholes with effective sealing depths of 4 and $8 \mathrm{~m}$, respectively, were significantly small and nearly equivalent, and the high-concentration CMM drainage period was $50 \mathrm{~d}$. When the effective sealing depth was increased to $16 \mathrm{~m}$, the methane flow and concentration of the QN 1-2 and QN 2-2 boreholes increased significantly compared to those of the QN 1-3 and QN 2-1 boreholes, and the high-concentration CMM drainage period was extended to approximately $80 \mathrm{~d}$. However, when the effective sealing depth of the QN 2-3 borehole was $18 \mathrm{~m}$, the methane flow and concentration remained unchanged, as did the high-concentration CMM drainage period. In addition, the sealing performance of the QN 1-2 borehole with a sealing depth of $16 \mathrm{~m}$ was notably superior to that of the QN 1-3 borehole with a sealing depth of $20 \mathrm{~m}$. The deterioration in the sealing performance with increasing sealing depth indicates that an effective sealing depth should be selected in the borehole design and construction
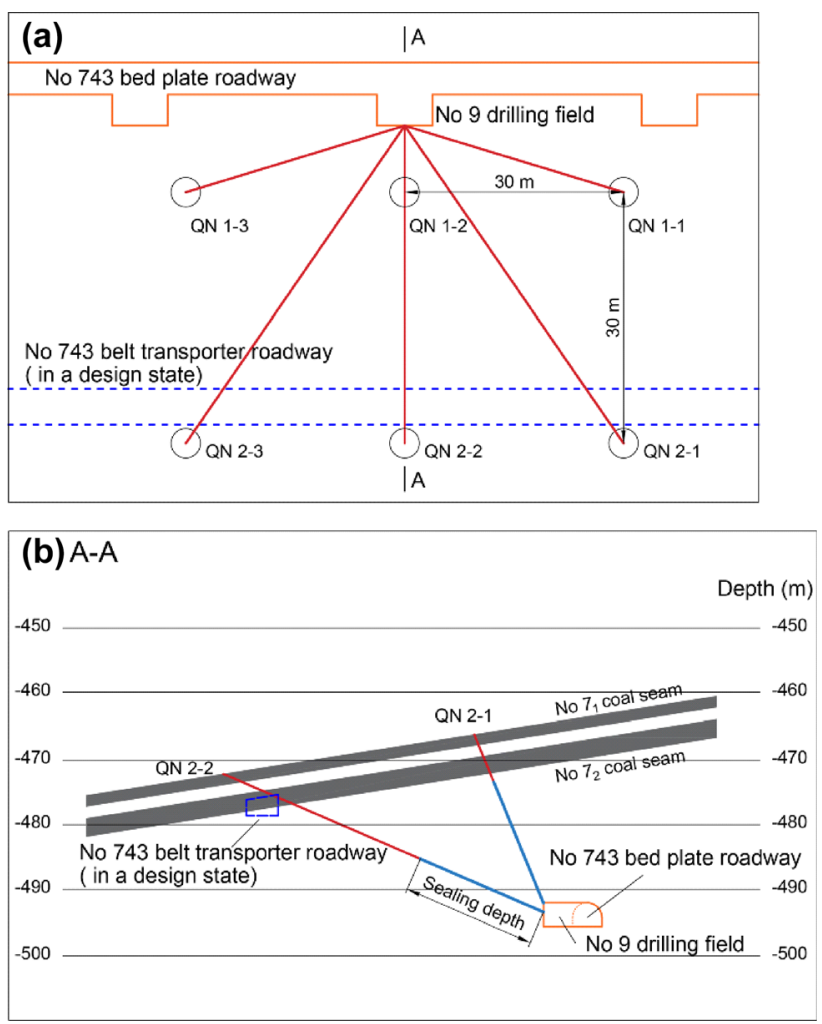

Fig. 8 Layout of experimental boreholes in Qinan coal mine: a plan; b section

processes, determined according to the construction angle of the borehole.

The effects of the sealing depth on the in-seam and crossing boreholes were similar. Increasing the sealing depth reduced the air leakage considerably by improving the resistance of the air migration in the fractures around the roadway; however, increasing the sealing depth did not improve the sealing performance considerably when the sealing depth exceeded the critical depth (low-permeability zone), and the length of the borehole drainage section decreased in that case. The methane drainage results validate the method for determining the sealing depth based on the stress distribution characteristics. In addition, although the effective sealing depth of the QN 1-3 borehole $(8 \mathrm{~m})$ was two times that of the QN 1-1 borehole $(4 \mathrm{~m})$, the methane drainage concentrations for the two boreholes were nearly the same, indicating that the effect of the borehole sealing section in the high-permeability zone on the borehole sealing performance is insignificant.

\subsection{CMM drainage for key sealing in low- permeability zone}

The field methane drainage results and the analysis of the permeability of the roadway surrounding rock indicated that the sealing section in the fracture and plastic zones- 
Table 2 Parameters of experimental boreholes in Qinan coal mine

\begin{tabular}{lllllll}
\hline Group & Borehole & Azimuth angle $\left(^{\circ}\right)$ & Dip angle $\left(^{\circ}\right)$ & Depth $(\mathrm{m})$ & Sealing depth $(\mathrm{m})$ & Effective sealing depth $(\mathrm{m})$ \\
\hline 1 & QN1-1 & -69 & 41 & 40 & 10 & 4 \\
& QN1-2 & 0 & 68 & 28 & 16 & 16 \\
2 & QN1-3 & +69 & 41 & 40 & 20 & 8 \\
& QN2-1 & -30 & 20 & 60 & 10 & 9 \\
& QN2-2 & 0 & 23 & 53 & 16 & 16 \\
& QN2-3 & +30 & 20 & 60 & 20 & 18 \\
\hline
\end{tabular}

Note: For the azimuth angle, the vertical line of the roadway was considered as the benchmark, and positive and negative angles correspond to clockwise and counterclockwise rotation, respectively
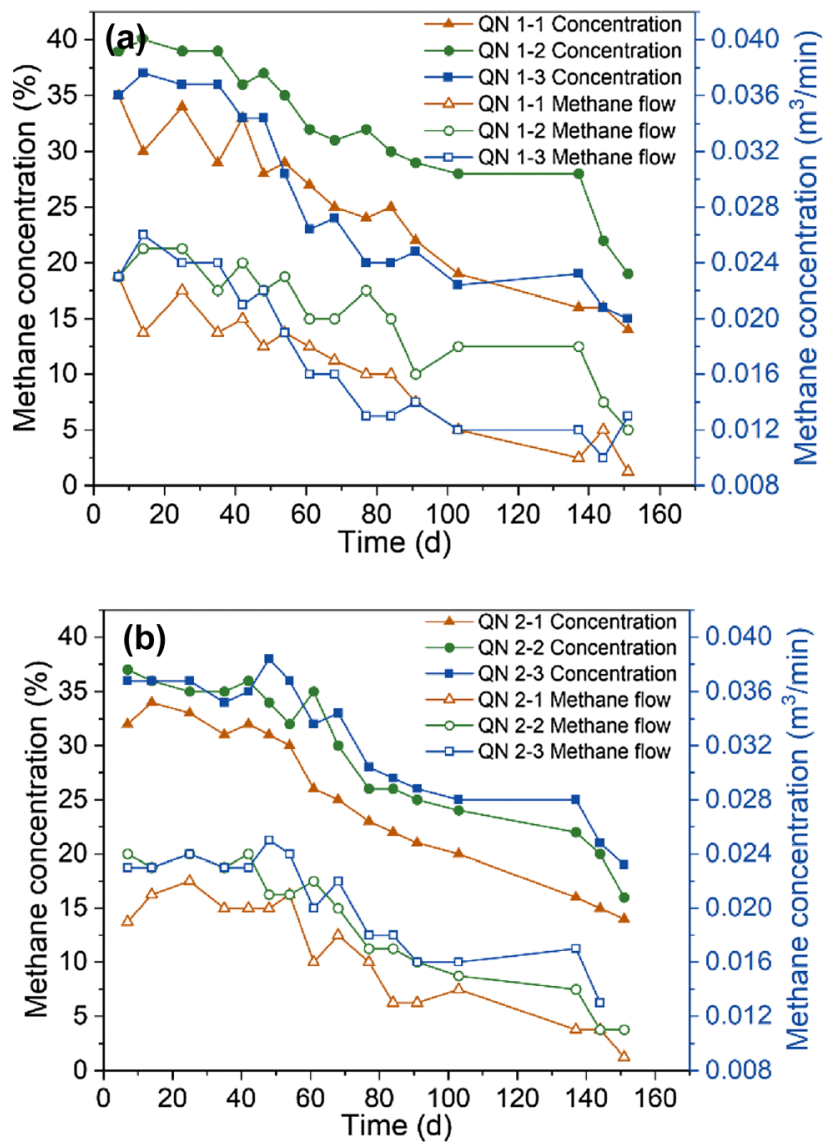

Fig. 9 Concentration-time curves of methane for different sealing depths in Qinan coal mine

with high permeability—contributed slightly to improving the borehole sealing performance. Therefore, a new sealing method for key sealing in the low-permeability zone was developed after determining the sealing depth. As shown in Fig. 10, the boundary between the stress concentration and stress relief zones was used as the starting point of the borehole sealing, and the depth of the stress peak point was selected as the sealing depth. The range of the stress concentration zones in the two test sites was 10-20 m, and the depth of the stress peak point in both cases was $16 \mathrm{~m}$. Therefore, the starting and ending depths of the borehole sealing section were 10 and $16 \mathrm{~m}$, respectively, and the sealing length was $6 \mathrm{~m}$. In this study, a group of boreholes was established in the Xutuan and Qinan coal mines, including a borehole with the full sealing length and one with key sealing in the low-permeability zone. The sealing depth in both cases was $16 \mathrm{~m}$, and the sealing lengths of full-sealing boreholes were $16 \mathrm{~m}$, while that of key-sealing boreholes were $6 \mathrm{~m}$.

The methane parameters in these boreholes were recorded for approximately 14 weeks, and the methane concentration varied as presented in Table 3 and Fig. 11 . The methane concentration in the borehole with full sealing length was larger than that in the borehole with key sealing in the low-permeability zone, and the decrease in the sealing length corresponded to an increase in the air leakage of the borehole, which may be related to the reduction in the air migration resistance caused by the shorter borehole leakage channel (Wang et al. 2020a). However, the maximum variation in the methane concentration under both sealing methods was less than $2 \%$, and the highconcentration CMM drainage periods were nearly equivalent. The results show that the sealing section in the lowpermeability zone is the key to borehole sealing. The methane drainage with the method of key sealing in the low-permeability zone considered in this study provides a flexible and feasible way to determine and adjust the sealing length and depth at the coal mine site, which helps in improving the borehole sealing performance, reducing the borehole sealing cost, and realizing safe, economical, and efficient CMM drainage.

\subsection{Implications for safety mining and environment}

The Chinese standard AQ 1027-2006 (Code for Coal Mine Gas Drainage) specifies the minimum requirements for the borehole sealing depth and length. Although the borehole sealing depth and length in many coal mines in China meet 


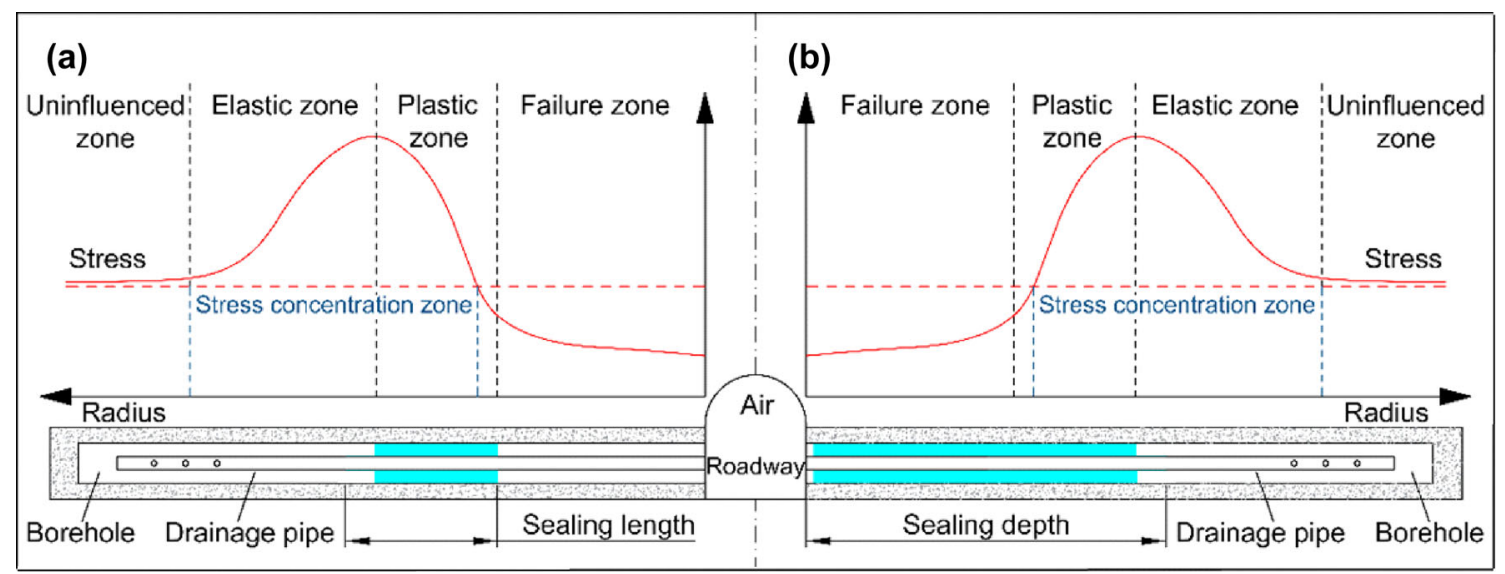

Fig. 10 Schematics of methane drainage for a key sealing in low-permeability zone and $\mathbf{b}$ full sealing length

Table 3 Methane concentration parameters of the boreholes for different sealing methods

\begin{tabular}{|c|c|c|c|c|c|c|}
\hline \multirow[t]{2}{*}{ Borehole } & \multicolumn{3}{|c|}{ Xutuan coal mine } & \multicolumn{3}{|c|}{ Qinan coal mine } \\
\hline & Max. $(\%)$ & Min. (\%) & Mean $(\%)$ & Max. (\%) & Min. (\%) & Mean $(\%)$ \\
\hline Full-sealing & 42.9 & 27.3 & 34.8 & 40.1 & 19.3 & 31.9 \\
\hline Key-sealing & 41.6 & 26.0 & 33.8 & 38.5 & 17.7 & 30.3 \\
\hline
\end{tabular}

the minimum requirements, they are generally determined via experience; for example, in both the Xutuan and Qinan coal mines, the borehole sealing depth is $12 \mathrm{~m}$. This process may lead to unsatisfactory borehole sealing performance, given that the geological conditions become increasingly complex with increasing mining depth. In China, the most important purpose of CMM drainage is to reduce the methane pressure to below $0.74 \mathrm{MPa}$ and the methane content to below $8 \mathrm{~m}^{3} / \mathrm{t}$. In this study, the methane flow increased with increasing borehole sealing depth, and the improvement of CMM drainage efficiency reduced the amount of time needed by gas controlling. Additionally, the CMM with a concentration below 30\% are always released into the atmosphere because it is difficult or uneconomical to utilize. The increased sealing performance will reduce greenhouse gas emissions. Taking the CMM drainage project in the Xutuan coal mine for example, the methane parameters in these boreholes were recorded once a week. As shown in Fig. 12, when the borehole sealing depth was increased from 12 to $16 \mathrm{~m}$, the high-concentration CMM drainage period increased from 53 to $81 \mathrm{~d}$, and the methane production in the high-concentration CMM drainage period increased from 1999 to $3321 \mathrm{~m}^{3}$, reducing the methane emissions by $1323 \mathrm{~m}^{3}$. Therefore, optimizing the sealing depth can improve methane drainage efficiency and reduce methane emissions from coal mines.

\section{Conclusions}

In this work, to improve CMM drainage efficiency, a new method for determining the sealing depth and length was developed to improve borehole sealing performance, and it was verified through field applications. The following main conclusions are drawn.

(1) The drilling parameters provided a reliable basis for studying the stress distribution around a roadway. Based on field tests and mechanics simulations, the stress distributions around roadways were analyzed and the roadway surrounding rock was divided into four zones.

(2) CMM drainage tests with different sealing depths were performed to determine a reasonable sealing depth, and the results showed that (1)increasing the sealing depth is effective for reducing the air leakage of the roadway and (2)the optimal sealing depth is at the stress peak. This method offers guidance for adjusting borehole sealing depths to adapt to different geological conditions.

(3) The overall borehole sealing performance is controlled primarily by the sealing section in the low-permeability zone. A CMM drainage method for key sealing in the low-permeability zone was proposed to improve the CMM extraction effect and reduce the construction amount, and its effectiveness was verified in field tests. 

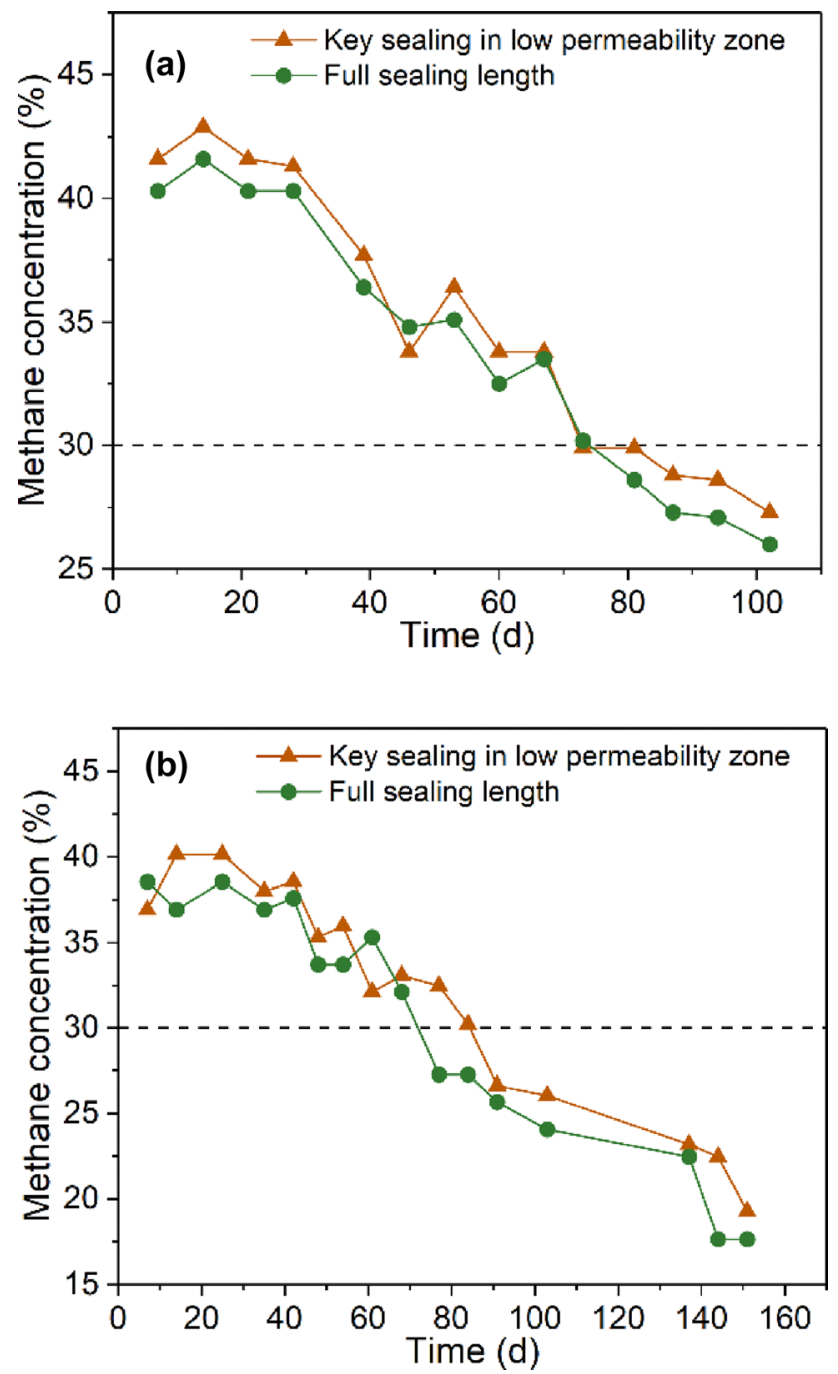

Fig. 11 Concentration-time curves of methane drainage for key sealing in low-permeability zone and full sealing length: a Xutuan and b Qinan coal mines

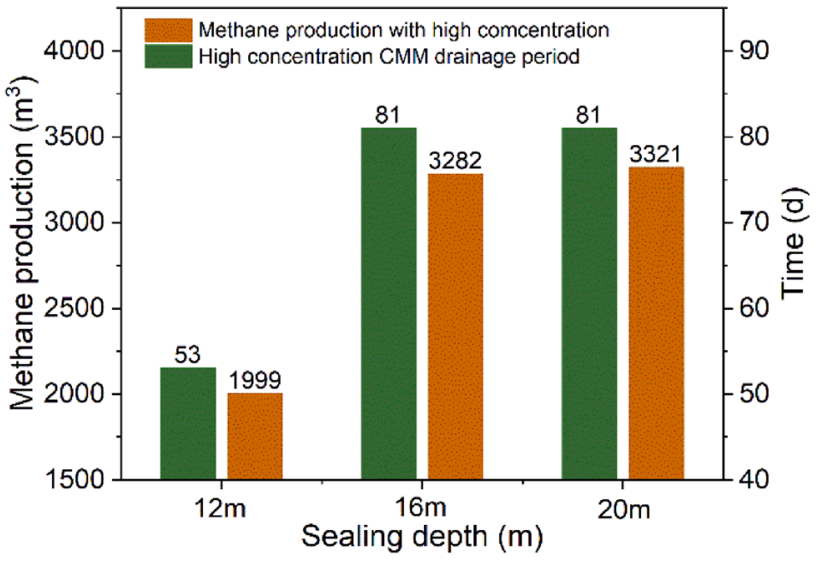

Fig. 12 Comparison of methane production and drainage efficiency with different borehole sealing depths
Authors' contributions YM: Methodology, Data curation, Investigation, Software, Writing — original draft, Writing — review \& editing. WL: Conceptualization, Methodology, Resources. HC: Investigation, Writing-review \& editing. LQ: Supervision, Software, Project administration. WZ: Investigation, Visualization, Writing-original draft.

Funding This research was supported by the National Natural Science Foundation of China (51974300), the Fundamental Research Funds for the Central Universities (2021YCPY0206 and 2020ZDPY0224), the Postgraduate Research \& Practice Innovation Program of Jiangsu Province (KYCX21_2467), and as a project funded by the Priority Academic Program Development of Jiangsu Higher Education Institutions.

Availability of data and materials The data supporting the findings can be found in the figures, tables, and manuscript.

\section{Declarations}

Competing interests The authors declare that they have no known competing financial interests or personal relationships that could have appeared to influence the work reported in this paper.

Open Access This article is licensed under a Creative Commons Attribution 4.0 International License, which permits use, sharing, adaptation, distribution and reproduction in any medium or format, as long as you give appropriate credit to the original author(s) and the source, provide a link to the Creative Commons licence, and indicate if changes were made. The images or other third party material in this article are included in the article's Creative Commons licence, unless indicated otherwise in a credit line to the material. If material is not included in the article's Creative Commons licence and your intended use is not permitted by statutory regulation or exceeds the permitted use, you will need to obtain permission directly from the copyright holder. To view a copy of this licence, visit http://creativecommons. org/licenses/by/4.0/.

\section{References}

Cai M, Kaiser PK (2014) In-situ rock spalling strength near excavation boundaries. Rock Mech Rock Eng 47:659-675

Chen W (2012) Analysis on relationship between stress and drill cutting weight using numerical modelling - a case study in Jinjiazhuang coal mine. Saf Sci 50:923-926

Fu D, Xu G, Ma L et al (2020) Gas generation from coal: taking Jurassic coal in the Minhe Basin as an example. Int J Coal Sci Technol 7:611-622

Fuenkajorn K, Daemen JJ (2012) Sealing of boreholes and underground excavations in rock. Springer, Berlin

Hao C, Cheng Y, Dong J et al (2018) Effect of silica sol on the sealing mechanism of a coalbed methane reservoir: New insights into enhancing the methane concentration and utilization rate. J Natl Gas Sci Eng 56:51-61

$\mathrm{Hu} \mathrm{S}$, Hao G, Feng G et al (2020) A method for improving the methane extraction concentrations of in-seam boreholes. Fuel 265:117006

Hu S, Zhou F, Liu Y et al (2015) Effective stress and permeability redistributions induced by successive roadway and borehole excavations. Rock Mech Rock Eng 48:319-332

Islam MR, Shinjo R (2009) Numerical simulation of stress distributions and displacements around an entry roadway with igneous intrusion and potential sources of seam gas emission of the 
Barapukuria coal mine, NW Bangladesh. Int $\mathrm{J}$ Coal Geol 78:249-262

Kalantari S, Hashemolhosseini H, Baghbanan A (2018) Estimating rock strength parameters using drilling data. Int J Rock Mech Min Sci 104:45-52

Karacan CÖ, Ruiz FA, Cotè M et al (2011) Coal mine methane: a review of capture and utilization practices with benefits to mining safety and to greenhouse gas reduction. Int $\mathrm{J}$ Coal Geol $86: 121-156$

Kholod N, Evans M, Pilcher RC et al (2020) Global methane emissions from coal mining to continue growing even with declining coal production. J Clean Prod 256:120489

Li H, Liu S, Chang H (2020a) Experimental research on the influence of working parameters on the drilling efficiency. Tunnel Undergr Space Technol 95:103174

Li Y, She L, Wen L et al (2020b) Sensitivity analysis of drilling parameters in rock rotary drilling process based on orthogonal test method. Eng Geol 270:105576

Liu H, Lin B, Jiang C (2019) A new method for determining coal seam permeability redistribution induced by roadway excavation and its applications. Process Saf Environ Prot 131:1-8

Liu P, Jiang Y, Fu B (2020) A novel approach to characterize gas flow behaviors and air leakage mechanisms in fracture-matrix coal around in-seam drainage borehole. J Natl Gas Sci Eng 77:103243

Liu Q, Cheng Y, Yuan L et al (2014a) A new effective method and new materials for high sealing performance of cross-measure CMM drainage boreholes. J Natl Gas Sci Eng 21:805-813

Liu Q, Cheng Y, Yuan L et al (2014b) CMM capture engineering challenges and characteristics of in-situ stress distribution in deep level of Huainan coalfield. J Natl Gas Sci Eng 20:328-336

Meng Z, Shi X, Li G (2016) Deformation, failure and permeability of coal-bearing strata during longwall mining. Eng Geol 208:69-80

National Energy Administration (2016) 13th Five-year plan on development and utilization of coalbed methane (coal mine methane). National Energy Administration

Wang H, Cheng Y, Wang W et al (2014) Research on comprehensive CBM extraction technology and its applications in China's coal mines. J Natl Gas Sci Eng 20:200-207

Wang H, Wang E, Li Z et al (2020a) Study on sealing effect of predrainage gas borehole in coal seam based on air-gas mixed flow coupling model. Process Saf Environ Prot 136:15-27

Wang K, Zhang J, Cai B et al (2019a) Emission factors of fugitive methane from underground coal mines in China: estimation and uncertainty. Appl Energy 250:273-282

Wang X, Tang Y, Wang S et al (2020b) Clean coal geology in China: research advance and its future. Int $\mathrm{J}$ Coal Sci Technol $7: 299-310$
Wang Z, Sun Y, Wang Y et al (2019b) A coupled model of air leakage in gas drainage and an active support sealing method for improving drainage performance. Fuel 237:1217-1227

Xia T, Zhou F, Liu J et al (2014) A fully coupled coal deformation and compositional flow model for the control of the pre-mining coal seam gas extraction. Int J Rock Mech Min Sci 72:138-148

Xue Y, Gao F, Liu X et al (2017) Permeability and pressure distribution characteristics of the roadway surrounding rock in the damaged zone of an excavation. Int $\mathrm{J}$ Min Sci Technol 27:211-219

Yang T, Li B, Ye Q (2018) Numerical simulation research on dynamical variation of permeability of coal around roadway based on gas-solid coupling model for gassy coal. Int J Min Sci Technol 28:925-932

Zhai C, Xu J, Liu S et al (2018) Investigation of the discharge law for drill cuttings used for coal outburst prediction based on different borehole diameters under various side stresses. Powder Technol 325:396-404

Zhang J, Zhai C, Zhong C et al (2019) Investigation of sealing mechanism and field application of upward borehole self-sealing technology using drill cuttings for safe mining. Saf Sci 115:141-153

Zhang K, Hou R, Zhang G et al (2016a) Rock Drillability assessment and lithology classification based on the operating parameters of a drifter: case study in a coal mine in China. Rock Mech Rock Eng 49:329-334

Zhang K, Sun K, Yu B et al (2016b) Determination of sealing depth of in-seam boreholes for seam gas drainage based on drilling process of a drifter. Eng Geol 210:115-123

Zhang Y, Hu S, Xia T et al (2020a) A novel failure control technology of cross-measure borehole for gas drainage: a case study. Process Saf Environ Prot 135:144-156

Zhang Y, Zou Q, Guo L (2020b) Air-leakage model and sealing technique with sealing-isolation integration for gas-drainage boreholes in coal mines. Process Saf Environ Prot 140:258-272

Zhao W, Wang K, Zhang R et al (2020) Influence of combination forms of intact sub-layer and tectonically deformed sub-layer of coal on the gas drainage performance of boreholes: a numerical study. Int J Coal Sci Technol 7:1-10

Zhao Y, Feng Z, Xi B et al (2015) Deformation and instability failure of borehole at high temperature and high pressure in hot dry rock exploitation. Renew Energy 77:159-165

Zheng C, Chen Z, Kizil M et al (2016) Characterisation of mechanics and flow fields around in-seam methane gas drainage borehole for preventing ventilation air leakage: a case study. Int J Coal Geol 162:123-138 